\title{
Response of hydrogenase enzymes (ALDH and ADH) in Trapa natans under physiological stress
}

\author{
Neha Pathania-Gagandeep Kaur, Joginder Singh, Ashish Vyas, Manoj Kumar*
}

Department of Biotechnology, Lovely Professional University, Jalandhar, India

Email: *manojjnu@gmail.com

Received 4 May 2012; revised 11 June 2012; accepted 2 July 2012

\begin{abstract}
The present study screens activity of different enzymes in Trapa natans under aerobic and anaerobic physiological conditions. Experimental analysis was carried out to assay the activities of ALDH and ADH in the seed extract of $T$. natans. These enzymes are associated with the alcohol metabolism of the $T$. natans. It was observed that a metabolic pathway shifts from aerobic respiration to anaerobic fermentation under anoxic conditions. Physiological stress related response in trapa seeds gives the leads to understand the other model for better fermentable products. During the experiment it was found that there is difference between the concenteration of enzymes in anaerobic and aerobic conditions. Concentration was check with the help of spectrophotometer at $340 \mathrm{~nm}$.
\end{abstract}

Keywords: ALDH; ADH; Anoxic Condition; Trapa natans

\section{INTRODUCTION}

Oxygen requirement in the seeds of higher plants is well understood for the natural growth. Although there are many examples of stress responsive growth and germination of seeds under have already been noticed by different group of researchers [1-4]. Most plants can tolerate anoxia for only short periods of time before irreparable damage occurs [5] but in the case of Trapa natans, as it mainly found in water, these conditions are more frequent and most obvious.

Under anaerobic conditions fermentative pathways get initiated and results into important fermentative products like ethanol, acetaldehyde, lactate etc. Plants which only survive under aerobic conditions shrink due to the cytoplasmic acidosis or harmful products like ethanol, acetaldehyde. But anaerobic plants can survive under these conditions and take advantages. Low oxygen availability alters the gene expression leads to cellular orientation

*Corresponding author.
[6,7]. Sachs et al. [8] detected in maize the presence of a small number of proteins called "transition polypeptides", they include alcohol dehydrogenase, aldehyde dehydrogenase, pyruvate decarboxylase etc in this class.

Present study explains the enzymes associated with anaerobic metabolism are eventually assayed to compare regulation of anaerobic metabolism for anoxia-tolerant and intolerant seeds of Trapa natans.

\section{MATERIALS AND METHODS}

\subsection{Plant Materials}

Trapa natans plants were collected from agricultural fields of Haryana, India. Seeds were collected by removing the rind and were used to prepare the extract.

\subsection{Preparation of the Extract for Enzymatic Activity Analysis}

Sample of fresh seeds provided aerobic conditions by maintaining them in closed flask, provided with continuous supply of air from the bottom. Another sample of fresh seeds was given anaerobic conditions by keeping them in filled bottle of concentrated ethanol, further incubated in dark room. The seeds were taken in replicates after day 3 , day 5 , day 7 , and day 9 respectively and grounded to powder. Finely grounded powder $(5.0 \mathrm{~g})$ from both the samples was taken in pre-chilled centrifuge tubes. Simultaneously $900 \mu$ l extraction buffers were added to both. The extract was then centrifuged at $5000 \mathrm{rpm}$ for the $30 \mathrm{~min}$. and supernatant was taken for enzyme assays.

\subsection{Enzyme Activity Test for ALDH (Aldehyde dehydrogenase)}

Aldehyde dehydrogenases (ALDH, EC 1.2.1.3) represent a group of enzymes, which may play a role in stress relevant detoxification processes. Method given by op den Camp and Kuhlemeier [9] was taken into consideration for estimation of ALDH activity. The extraction buffer contained $100 \mathrm{mM}$ HEPES (pH 7.4), 1 mM EDTA, 
$2 \mathrm{mM}$ dithiothreitol, and $0.1 \%(\mathrm{v} / \mathrm{v})$ Triton $\mathrm{X}-100$ was prepared. For the activity assay, $100 \mathrm{ml}$ extract was added to reaction mixture containing $100 \mathrm{mM}$ sodium pyrophosphate ( $\mathrm{pH} 9.5)$ and 1.5 mM NAD. Acetaldehyde $(99.5 \%, 5.6 \mathrm{ml})$ was added to start the reaction. NAD reduction was monitored at $340 \mathrm{~nm}$ at $30^{\circ} \mathrm{C}$ for $2.5 \mathrm{~min}$.

\subsection{Enzyme Activity Test for ADH (Alcohol dehydrogenase)}

Total ADH activity was analyzed using the modified procedures described by Ella et al. [10]. The extraction buffer contained $100 \mathrm{mM}$ TRIS-HCl (pH 9.0), $20 \mathrm{mM}$ $\mathrm{MgCl}_{2}, 0.1 \%$ (v/v) $\beta$-mercaptoethanol, $100 \mathrm{mM}$ leupep tin, $1 \mathrm{mM}$ PMSF, and $100 \mathrm{mM}$ TPCK (N Tosyl-L-phenylalanine chloromethyl ketone). For the activity assay, 20 $\mathrm{ml}$ extract was mixed to a reaction mixture containing 50 $\mathrm{mM}$ TRIS-HCl (pH 9.0) and $1 \mathrm{mM}$ NAD in a $1 \mathrm{ml} \mathrm{cu-}$ vette. Ethanol $(50 \mathrm{ml})$ was added finally to initiate the reaction. ADH activity was assayed in the acetaldehyde synthesis direction and NAD reduction was monitored at $340 \mathrm{~nm}$ at $30^{\circ} \mathrm{C}$ for $2.5 \mathrm{~min}$.

\section{RESULTS}

The activity of ALDH and ADH in seeds of T. natans was quantified spectrophotometrically. Concentration of $\mathrm{ALDH}$ and $\mathrm{ADH}$ was found to be increased in anaerobic condition as compare to aerobic conditions. This was perceived by OD analysis taken from the samples treated for different days (Figures 1 and 2). These enzymes are associated with the alcohol metabolism. It was observed that a metabolic pathway shifts from aerobic respiration to anaerobic fermentation under anoxic conditions. During the experiment it was found that there is difference between the concentration of enzymes in anaerobic and aerobic conditions. The screening of enzymes in the anaerobic and aerobic conditions has shown that the enzyme activity of ALDH and ADH in anaerobic condition was more in comparison to aerobic conditions. Activity of the both enzymes altered due to the high exposure under anaerobic environment. Both enzymes help plant to endure under the water lodged conditions.

\section{DISCUSSION}

The idea of a unified theory of tolerance to anoxia seems to have no theoretical ground, since distinct tolerance mechanisms, depending on the species and even on the tissue specific. Studies on the variation of the adenylate energy load, imposed on vegetable tissues by anoxia, confirms this variable as the only common possible ways [11-15]. Plant cells have the physiological potential to trigger the mechanism under anoxia which maintains satisfactory energy loads under stress [16]. No energy load studies were performed yet with accuracy. This study indicates an active anaerobic metabolism and different tolerance strategy which provides the base to enzymatic involvement under certain physiological scarcity. These two enzymes are constitutive and possess active involvement in the seedling tolerance to anoxia. The frequent occurrence of $T$. natans in areas periodically waterlogged rises speculation about the existence of mechanisms of anticipation to anaerobic stress. Damage during the metabolic adjustment would be avoided by the presence of the constitutive alcohol dehydrogenase and aldehyde dehydrogenase enzymes in all tissues. The seedlings are not developed under anoxia moreover had the potential to resume the growth after aeration. Anoxic

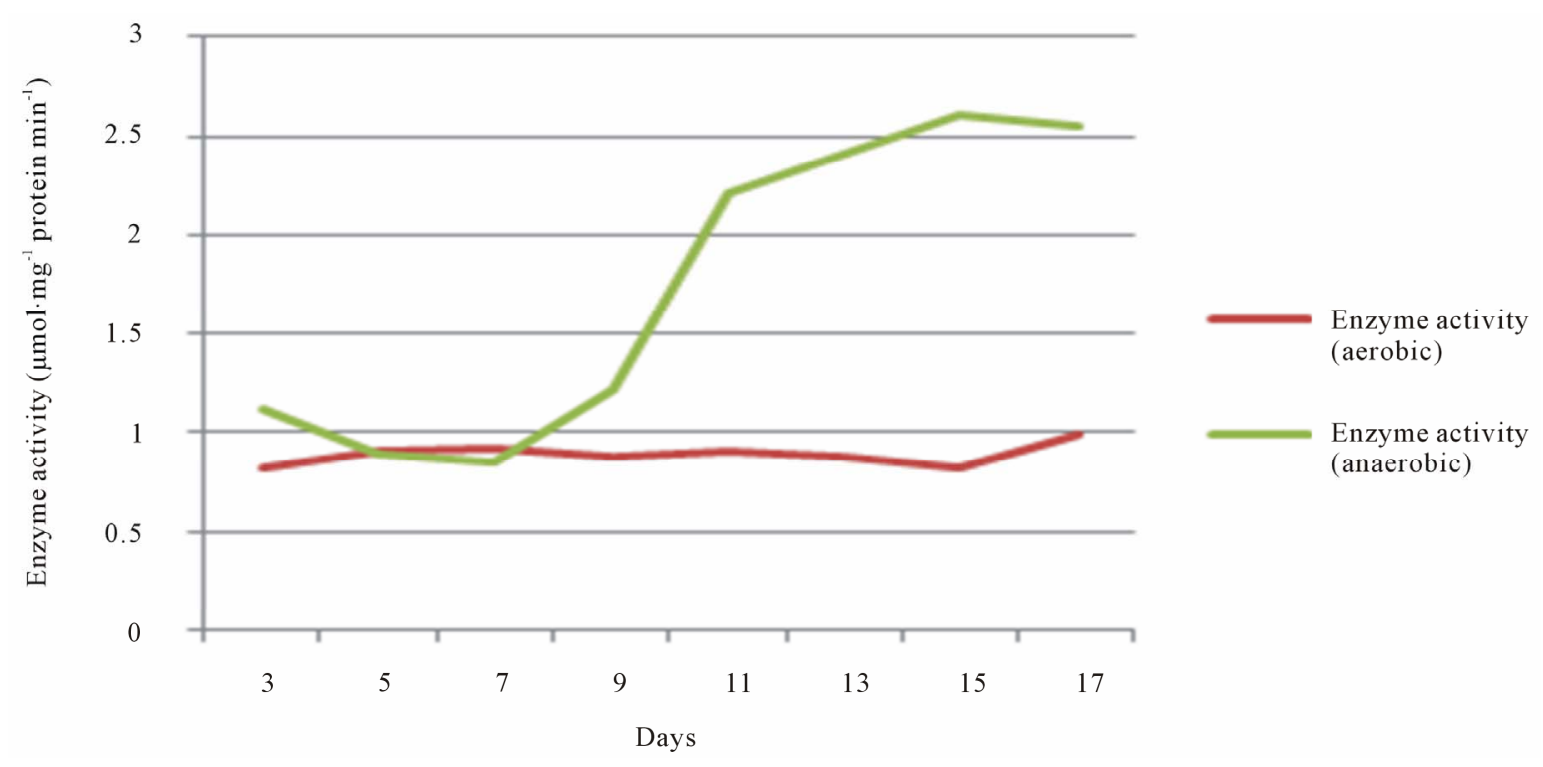

Figure 1. The variation of Aldehyde dehydrogenase (ALDH) activity in anaerobic and aerobic conditions. 


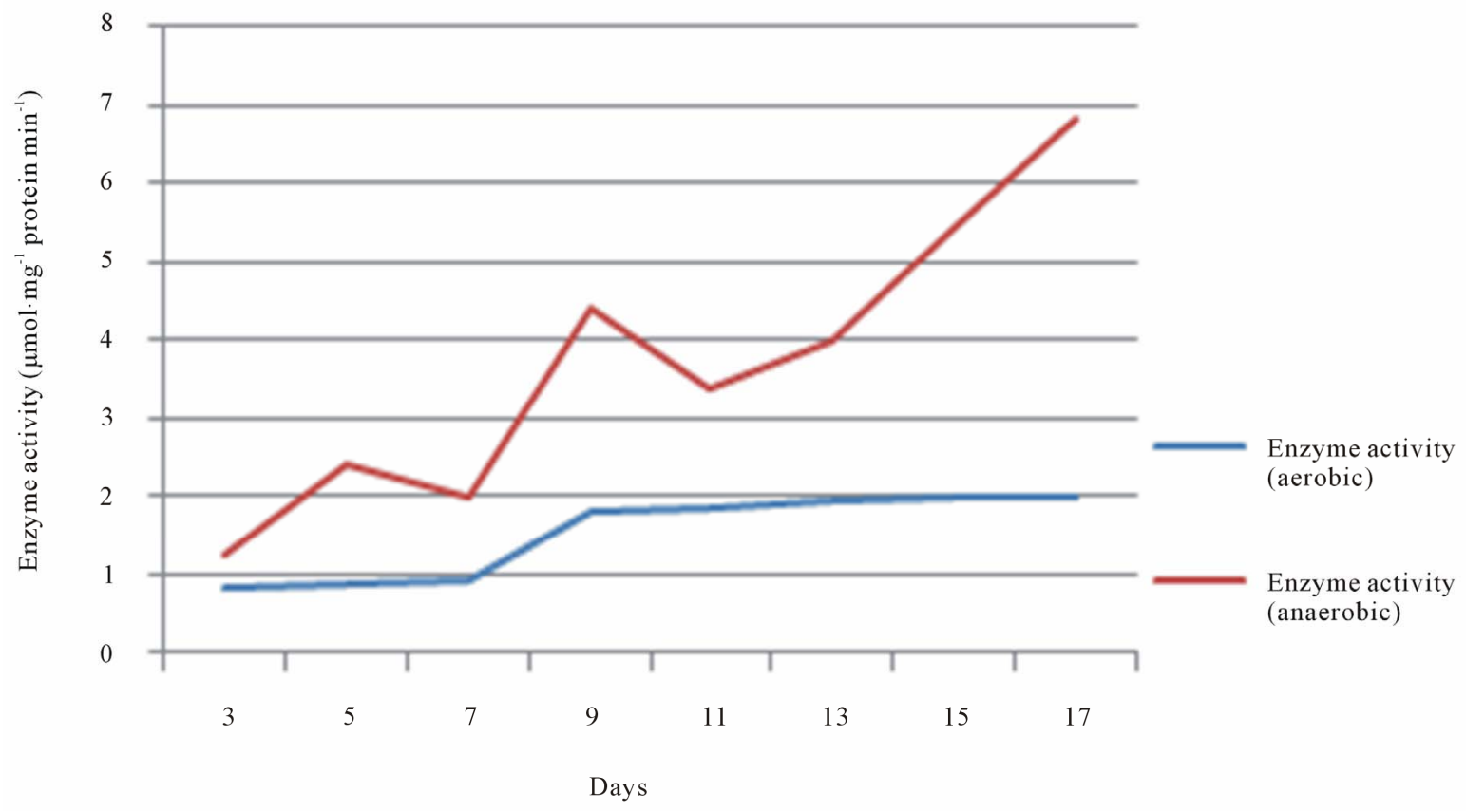

Figure 2. The variation of Alcohol dehydrogenase (ADH) activity in aerobic and anaerobic conditions.

tolerance seems to be associated with the adequate adjustment of the energetic load of adenylate and NAD recycling to preserve cellular integrity in the absence of oxygen. It could be a possibility that ATP supply continues even in the absence of oxygen at a slower rate, which is required for maintenance and for the synthesis of various metabolites.

\section{CONCLUSION}

The screening of enzymes in the anaerobic and aerobic conditions has shown that the enzyme activity of ALDH and ADH in anaerobic condition was more in comparison to aerobic conditions. Activity of the both enzymes altered due to the high exposure under anaerobic environment. Both enzymes helps plant to endure under the water lodged conditions. ADH does the inter conversion between alcohols and aldehydes or ketones with the reduction of nicotinamide adenine dinucleotide $\left(\mathrm{NAD}^{+}\right.$to $\mathrm{NADH}$ ) whereas ALDH converts acetaldehyde into carboxylic acids, which are less toxic for the plants, thus helping plants to survive and sustain themselves under anerobic condition.

\section{REFERENCES}

[1] Rolletschek, H., Stangelmayer, A. and Borisjuk, L. (2009) Methodology and significance of microsensor-based oxygen mapping in plant seeds-An Overview. Sensors, 9, 3218-3227. doi: $10.3390 / \mathrm{s} 90503218$

[2] Hosnedl, V. and Honsová, H. (2002) Barley seed sensitivity to water stress at germination stage. Plant, Soil and
Environment, 48, 293-297.

[3] Magneschi, L. and Perata, P. (2008) Rice germination and seedling growth in the absence of oxygen. Annals of Botany, 103, 181-196. doi:10.1093/aob/men121

[4] Ismail, A.M., Ella, E.S., Vergara, G.V. and Mackill, D.J. (2009) Mechanisms associated with tolerance to flooding during germination and early seedling growth in rice (Oryza sativa). Annals of Botany, 103, 197-209. doi:10.1093/aob/men211

[5] Yordanova, R.Y. and Popova, L.P. (2001) Photosynthetic response of barley plants to soil flooding. Photosynthetica, 39, 515-520. doi:10.1023/A:1015643710177

[6] Sasidharan, R. and Mustroph, A. (2011) Plant oxygen sensing is mediated by the N-end rule pathway: A milestone in plant anaerobiosis. Plant Cell, 23, 4173-4183. doi: $10.1105 /$ tpc. 111.093880

[7] Subbaiah, C.C. and Sachs, M.M. (2003) Calcium-mediated responses of maize to oxygen deprivation. Russian Journal of Plant Physiology, 50, 752-761. doi:10.1023/B:RUPP.0000003273.44823.cd

[8] Sachs, M.M., Freeling, M. and Okimoto, R. (1980) The anaerobic proteins of maize. Cell, 20, 761-767. doi:10.1016/0092-8674(80)90322-0

[9] op den Camp, R.G., and Kuhlemeier, C. (1997) Aldehyde dehydrogenase in tobacco pollen. Plant Molecular Biology, 35, 355-365.

[10] Ella, E.S., Valdez, A.P., Reyes, R.V., Greenway, H. and Setter, T.L. (1993) Importance of several enzymes in limitation of alcoholic fermentation of rice under anoxia. Proceedings of the 6th Annual Meeting of the International Program on Rice Biotechnology, Chiang Mai, 1-5 February 1993.

[11] Rolletschek, H., Borisjuk, L., Koschorreck, M., Wobus, 
U. and Weber, H. (2002) Legume embryos develop in a hypoxic environment. Journal of Experimental Botany, 53, 1099-1107. doi:10.1093/jexbot/53.371.1099

[12] Gibbs, J., Morell, S., Valdez, A., Setter, T.L. and Greenway, H. (2000) Regulation of alcoholic fermentation in coleoptiles of two rice cultivars differing in tolerance for anoxia. Journal of Experimental Botany, 51,785-796. doi:10.1093/jexbot/51.345.785

[13] Ling, J., Ming-Yu, H., Chun-Ming, W. and Jian-Min, W. (2004) Quantitative trait loci and epistatic analysis of seed anoxia germinability in rice (Oryza sativa). Rice Science, 11, 238-244.

[14] Ueno, R., Urano, N., Suzuki, M. and Kimura, S. (2002)
Isolation, characterization, and fermentative pattern of a novel thermotolerant Prototheca zopfii var. hydrocarbonea strain producing ethanol and $\mathrm{CO}_{2}$ from glucose at $40^{\circ} \mathrm{C}$. Archives of Microbiology, 177, 244-250. doi:10.1007/s00203-001-0384-0

[15] Parent. C., Capelli, N., Berger, A., Crèvecoeur, M. and Dat, J.F. (2008) An overview of plant responses to soil waterlogging. Plant Stress, 2, 20-27.

[16] Rawyler, A., Arpagaus, S. and Braendle, R. (2002) Impact of oxygen stress and energy availability on membrane stability of plant cells. Annals of Botany, 90, 499507. doi:10.1093/aob/mcf126 